\title{
Macrophage-derived interleukin-1beta promotes human breast cancer cell migration and lymphatic adhesion in vitro
}

\author{
Sarah J. Storr ${ }^{1} \cdot$ Sabreena Safuan $^{1,2} \cdot$ Narmeen Ahmad $^{1} \cdot$ Mohammed El-Refaee $^{3,4}$. \\ Andrew M. Jackson ${ }^{3}$ Stewart G. Martin ${ }^{1}$
}

Received: 3 October 2016 / Accepted: 21 May 2017 / Published online: 27 May 2017

(C) The Author(s) 2017. This article is an open access publication

\begin{abstract}
Lymphovascular invasion (LVI), encompassing blood and lymphatic vessel invasion, is an important event in tumourigenesis. Macrophages within the tumour microenvironment are linked to the presence of LVI and angiogenesis. This study investigates the role of macrophage-derived, caspase-1-dependent interleukin-1beta (IL-1 $\beta$ ) in an in vitro model of LVI. IL- $1 \beta$ significantly augmented the adhesion and transmigration of breast cancer cell lines MCF7 and MDA-MB-231 across endothelial cell barriers. MDAMB-231 and MCF7 showed a higher percentage of adhesion to lymphatic endothelial cells than blood endothelial cells following endothelial cell IL-1 $\beta$ stimulation $(P<0.001$ and $P<0.0001$, respectively). Supernatants from activated
\end{abstract}

Sarah J. Storr and Sabreena Safuan contributed equally to this work.

Stewart G. Martin

stewart.martin@nottingham.ac.uk

1 Division of Cancer and Stem Cells, Translational and Radiation Biology Research Group, School of Medicine, Academic Clinical Oncology, University of Nottingham, Nottingham University Hospitals NHS Trust, City Hospital Campus, Nottingham NG5 1PB, UK

2 Present Address: Health Campus, School of Health Sciences, Universiti Sains Malaysia, 16150 Kubang Kerian, Kelantan, Malaysia

3 Division of Cancer and Stem Cells, Host-Tumour Interactions Group, School of Medicine, Academic Clinical Oncology, University of Nottingham, Nottingham University Hospitals NHS Trust, City Hospital Campus, Nottingham NG5 1PB, UK

4 Present Address: Medical Biotechnology Department, Genetic Engineering and Biotechnology Research Institute, the City for Scientific Research and Technology Applications, Alexandria, Egypt macrophages increased the adhesion of tumour cells to lymphatic and blood endothelium. Secretion of IL-1 $\beta$ was caspase-1 dependent, and treatment with caspase-1 inhibitor reduced IL- $1 \beta$ production by $73 \%$ and concomitantly reduced tumour cell adhesion to levels obtained with resting macrophages. Transmigration of MDA-MB-231 cells across blood and lymphatic endothelial monolayers was significantly increased following IL-1 $\beta$ stimulation. Furthermore, supernatants from activated macrophages increased transmigration of MDA-MB-231 cells across endothelial monolayers, which was abolished by caspase-1 inhibition. IL- $1 \beta$ stimulation of tumour cells significantly increased their migratory ability and a significant increase in migration was observed when MDA-MB-231 cells were stimulated with macrophage conditioned media (two of three donors). Results demonstrate that macrophage production of IL-1 $\beta$ plays an important role in the migration of breast cancer cells and their adhesion to, and transmigration across, blood and lymphatic endothelial cells. Results suggest that IL- $1 \beta$ may play a role in the adhesion to lymphatic endothelial cells in particular.

Keywords Interleukin-1 - Breast cancer - Macrophage · Vascular invasion $\cdot$ Caspase-1

$\begin{array}{ll}\begin{array}{l}\text { Abbreviations } \\ \text { bFGF }\end{array} & \begin{array}{l}\text { Basic fibroblast growth factor } \\ \text { Common lymphatic endothelial and } \\ \text { vascular endothelial receptor }\end{array} \\ \text { EBM } & \begin{array}{l}\text { Endothelial basal media } \\ \text { Epidermal growth factor }\end{array} \\ \text { HGF } & \begin{array}{l}\text { Hypoxia-inducible factor } \\ \text { Human microvascular endothelial } \\ \text { cells }\end{array} \\ \text { HMEC-1 } & \begin{array}{l}\text { Neonatal dermal lymphatic microvas- } \\ \text { cular endothelial cells }\end{array}\end{array}$


hTERT-LEC Human telomerase reverse transcriptase immortalised lymphatic endothelial cells
HUVEC

ICAM-1

ICE

IL

IL-1 $\beta$

LPS

LVI

M-CSF

PBMC

STR

TDL

TNF

VCAM-1

VEGF
Human umbilical cord vein endothelial cells

Intracellular adhesion molecule

IL- $1 \beta$-converting enzyme

Interleukin

Interleukin-1beta

Lipopolysaccharide

Lymphovascular invasion

Macrophage colony stimulating factor

Peripheral blood mononuclear cells

Short tandem repeat

Tumour-derived lysate

Tumour necrosis factor

Vascular cell adhesion molecule

Vascular endothelial growth factor

\section{Introduction}

Lymphovascular invasion (LVI), encompassing both blood and lymphatic vessel invasion, is an important event in tumourigenesis and is an initial prerequisite step in metastasis. LVI is strongly associated with adverse patient prognosis in a number of tumour types, with studies showing that in certain tumour types, including breast cancer and melanoma, LVI occurs more frequently in lymphatic vessels as opposed to blood vessels [1-4]. The presence of macrophages within the tumour microenvironment has been linked to the presence of LVI and angiogenesis [1, $5,6]$. Macrophages are recruited by chemotactic factors expressed by tumours and the factors they express can affect tumour cell behaviour; some of the most widely described factors produced by macrophage that can alter angiogenesis are vascular endothelial growth factor (VEGF), and angiopoietin 1 (reviewed in [7]). Certain studies have reported that perivascular macrophages are involved in tumour cell intravasation without concomitant induction of angiogenesis [8].

Despite the link between immune cells within the tumour environment and the presence of LVI only a small number of factors have been identified that may have the ability promote vascular invasion, with most studies focussing upon factors that potentially influence blood vessel invasion. Cytokines are a loose category of small glycoproteins, including interleukins, interferons, chemokines and tumour necrosis factor (TNF). They are produced by a wide range of cells, notably immune cells and also endothelial cells, fibroblasts, and various tumour and stromal cells. A number of cytokines, such as interleukin (IL)-8 and TNF$\alpha$, are expressed at high levels by macrophages and can reportedly alter both angiogenesis and metastatic dissemination of tumour cells $[9,10]$.

The interleukin (IL)- 1 superfamily consists of IL- $1 \alpha$, IL-1 $\beta$ and others such as IL-18 and IL-13; and IL1-RA (receptor agonist) which functions to modulate IL- $1 \alpha$ and IL- $1 \beta$ activity (reviewed in [11]). IL- $1 \beta$ is a multifunctional pro-inflammatory cytokine principally produced by hematopoietic cells such as macrophages and monocytes, and also by epithelial cells, and expression is associated with angiogenesis and the invasive abilities of tumour cells $[12,13]$. IL-1 $\beta$ is linked to increased metastasis in various in vivo models [14] and has been linked with bone-homing in breast cancer. IL-1 $\beta$ expression has been shown to be expressed in the breast tumour microenvironment, at higher levels in invasive breast lesions than benign conditions and ductal in situ carcinoma $[13,15]$. Caspase-1, or IL-1 $\beta$-converting enzyme (ICE), is a cysteine protease responsible for activation of the IL- $1 \beta$ and IL-18 precursors to the pro-inflammatory active cytokines. Studies have suggested that caspase-1 expression is decreased in prostate cancer [16] and colon cancer [17].

This study aimed to investigate whether IL- $1 \beta$ can differentially modulate in vitro tumour cell adhesion and transmigration to, and across, blood and lymphatic endothelium and to assess its ability to alter tumour cell migration. We also sought to determine the effect on these phenotypic endpoints following stimulation with macrophage conditioned media alone and in combination with a caspase-1 inhibitor.

\section{Materials and methods}

\section{Cell lines and culture}

Breast cancer cell lines MCF7 and MDA-MD-231, large vein endothelial cells from human umbilical cords (HUVEC), human microvascular endothelial cells hMEC1, human telomerase reverse transcriptase immortalised lymphatic endothelial cells (hTERT-LEC) and neonatal dermal lymphatic microvascular endothelial cells (HMVEC-dLy Neo) were used in this study.

Breast cancer cell lines were obtained from the ATCC and used within a 15 passage window. MCF-7 were maintained in RPMI-1640 (Sigma), 10\% iron-supplemented donor calf serum (PAA laboratories) with $1 \%$ penicillin/streptomycin (Sigma). MDA-MB-231 were maintained in minimal essential medium EAGLE (Sigma), $0.1 \mathrm{mM}$ non-essential amino acids solution (Sigma), $2 \mathrm{mM}$ L-glutamine (Sigma), 1\% penicillin/streptomycin and $1 \%$ iron-supplemented donor calf serum. HUVEC were isolated as previously described [18, 19] and used 
between passage 2 and 6. HUVEC were maintained in $37 \%$ nutrient mixture F-12 HAM media (Sigma) in sterile water containing 3.7\% 199 media (Sigma), 20\% ironsupplemented donor calf serum, $1 \%$ sodium bicarbonate (Sigma), $14 \mathrm{mM}$ HEPES (Sigma), $2 \mathrm{mM}$ L-glutamine, $1 \%$ penicillin/streptomycin, $7.5 \mathrm{U} / \mathrm{ml}$ heparin (CP Pharmaceuticals), $25 \mathrm{ng} / \mathrm{ml}$ epidermal growth factor (EGF) (Peprotech) and $12.5 \mathrm{ng} / \mathrm{ml}$ basic fibroblast growth factor (bFGF) (Peprotech). Human microvascular endothelial cells hMEC-1 [20], obtained from ATCC, were grown in endothelial basal medium (Lonza, USA) with $10 \%$ ironsupplemented donor calf serum, $1 \mu \mathrm{g} / \mathrm{ml}$ hydrocortisone (Sigma), $10 \mathrm{ng} / \mathrm{ml} \mathrm{EGF} \mathrm{and} 1 \%$ penicillin/streptomycin and used between passage 4 and 18. hTERT-LEC were a kind gift from Nissato and Pepper [19, 21, 22] and were maintained in endothelial basal media (EBM) supplemented with the EGM-2 bullet kit (Lonza) and used between passage 27 and 34. HMVEC-dLy Neo (Lonza), a primary lymphatic cell line, was cultured in the same medium as hTERT-LEC and used between passage 4 and 6. Cell lines were routinely tested for mycoplasma and tumour cells have been subsequently verified using multiplex short tandem repeat (STR) system (Powerplex 16, Promega).

Tumour-conditioned media were generated from confluent tumour cell monolayers which were then cultured in HUVEC or hTERT-LEC basal medium without serum or growth factors for $24 \mathrm{~h}$. Prior to experimental use, tumour-conditioned media were supplemented with ironsupplemented donor calf serum and $50 \mathrm{U} / \mathrm{ml}$ polymyxinBsulphate (Sigma). Tumour-derived lysate (TDL), used for macrophage stimulation, was generated from $1 \times 10^{7}$ cells subjected to five cycles of freeze-thaw using liquid nitrogen and a $37{ }^{\circ} \mathrm{C}$ water bath. Debris was removed by centrifugation and cleared lysates stored at $-80{ }^{\circ} \mathrm{C}$.

Healthy donor peripheral blood, obtained with the approval of the relevant ethical review board (BT20052010, University of Nottingham Medical School Ethics Committee), was fractionated using Histopaque 1077 (Sigma) to obtain peripheral blood mononuclear cells (PBMC) [19, 23]. Monocytes were isolated from PBMC using paramagnetic particles conjugated with anti-CD14 antibodies (Miltenyi Biotec) and were $>95 \%$ pure as determined by flow cytometry. Macrophages were generated by culturing CD14 + monocytes for 6 days in RPMI-1640 medium with $10 \%$ foetal calf serum in the presence of $50 \mathrm{ng} / \mathrm{ml}$ of macrophage colony stimulating factor (M-CSF) (Peprotech) in Teflon flasks (Thermo Scientific). Macrophage phenotype was confirmed by flow cytometry (CD68+, CD14+, MHC II+) and conditioned media harvested on day 7 . IL- $1 \beta$ production by macrophages was induced by stimulating cells with tumour-derived lysate, lipopolysaccharide (LPS) (Invivogen) and a combination of tumour-derived lysate and LPS with and without caspase-1 inhibitor (R\&D Systems).

\section{Static adhesion and migration assays}

The assays have been described previously [19]. Briefly, static adhesion assays used a confluent endothelial monolayer that remained unstimulated, or was stimulated with IL-1 $\beta$ for $24 \mathrm{~h}$. Tumour cell adhesion was assessed after 35 min, following cell labelling with $1 \mu \mathrm{M}$ of Cell Tracker Green CMFDA (Invitrogen). Adherent tumour cells were counted using a fluorescence microscope (Nikon). Two fields of view were counted in each well at $20 \times$ magnification. Results were expressed as the percentage of cells adhered relative to control. PBMC adhesion controls were run immediately prior to each experiment to demonstrate that the endothelial cells and cytokine were responding appropriately. In migration assays, a confluent tumour cell monolayer remained unstimulated or was stimulated with IL-1 $\beta$ (5 ng/ $\mathrm{ml})$ for $24 \mathrm{~h}$. Mitomycin C (Sigma) was included $(10 \mu \mathrm{g} / \mathrm{ml})$ to inhibit cellular proliferation. Migration was monitored at different time points following a scratch to create an area devoid of adherent cells. Percentage reduction of the scratch area at different time points was measured using ImageJ $1.43 \mathrm{u}$ software (National Institute of Health).

\section{Transmigration assay}

A confluent endothelial cell monolayer was grown on Boyden Chamber Transwell inserts and remained unstimulated or was stimulated with IL-1 $\beta(10 \mathrm{ng} / \mathrm{ml})$ for $24 \mathrm{~h}$. The confluency and integrity of the endothelial barrier was demonstrated by preventing lucifer yellow leakage (Sigma). Tumour cell transmigration was assessed following cell labelling with $5 \mathrm{nM}$ of Cell Tracker Green CMFDA (Invitrogen). Transmigration was monitored, by counting cells on the underside of the chamber, after $16 \mathrm{~h}$ using a fluorescence microscope (Nikon). Experiments were conducted twice, both in duplicate.

\section{Elisa}

Expression of IL-1 $\beta$ in tumour conditioned media and macrophage conditioned media was conducted using a human IL-1 $/$ /IL-1F2 duoset ELISA development kit (R\&D Systems) according to the manufacturers' protocols. Briefly, a 96-well plate was coated with capture antibody overnight and the plate was washed and blocked with bovine serum albumin. Samples and IL- $1 \beta$ recombinant protein standard were added to the plate for $2 \mathrm{~h}$. This was followed by detection antibody for $2 \mathrm{~h}$ and streptavidin-HRP for $20 \mathrm{~min}$, with each step preceded by a wash. Colour change was achieved by the addition of substrate followed by a stop solution, and the plate was read at $450 \mathrm{~nm}$ on a BMG Fluostar Optima (BMG Labtech). 


\section{Statistics}

Data analysis was performed in Microsoft Excel 2007 and Graph Pad Prism. Statistical significance was determined using the independent samples $t$ test (two tailed), $P>0.05$ was deemed significant in this study.

\section{Results}

\section{Tumour cell adhesion to endothelial cells is increased by IL-1 $\beta$}

Conditioning blood or lymphatic endothelial cells with IL-1 $\beta$ for $24 \mathrm{~h}$ significantly increased the adhesion of both MDA-MB-231 and MCF7 cells (Fig. 1a, b). Both
MDA-MB-231 and MCF7 showed a higher percentage of adhesion to lymphatic endothelial cells than blood endothelial cells following endothelial cell IL-1 $\beta$ stimulation $(P<0.001$ and $P<0.0001$, respectively). Adhesion levels of tumour cell lines to endothelial cell models under control conditions have been previously published [19]. As with endothelial cell stimulation, 24-h IL-1 $\beta$ stimulation of tumour cells alone caused significant increase of both MDA-MB-231 and MCF7 adhesion (Fig. 1) to blood and lymphatic endothelial cells with MDA-MB-231 tumour cells having a significantly higher level of adhesion to lymphatic endothelial cells. When both tumour cells and endothelial cells were simultaneously conditioned with IL- $1 \beta$, adhesion was more markedly increased than when following stimulation of either cell type alone (Fig. 1e).
Fig. 1 Tumour cell adhesion to blood and lymphatic endothelium with and without IL-1 $\beta$ stimulation. a MDA-MB-231 and $\mathbf{b}$ MCF7 adhesion to IL- $1 \beta$ stimulated HUVEC (grey), hMEC-1 (grey striped), hTERTLEC (black) and HMVEC-dLy Neo (black striped) endothelial cells. c IL-1 $\beta$ stimulated MDAMB-231 and $\mathbf{d}$ IL-1 $\beta$ stimulated MCF7 adhesion to unstimulated endothelial cells. e IL-1 $\beta$ stimulated MDA-MB-231 adhesion to IL-1 $\beta$-stimulated hMEC-1 (grey striped) or hTERT-LEC (black) cells. Statistical significance $(P<0.05)$ determined by $t$ test compared to control group is indicated by an asterisk, error bars represent standard deviation. Statistical significance between blood and lymphatic endothelium is represented by double dagger
A

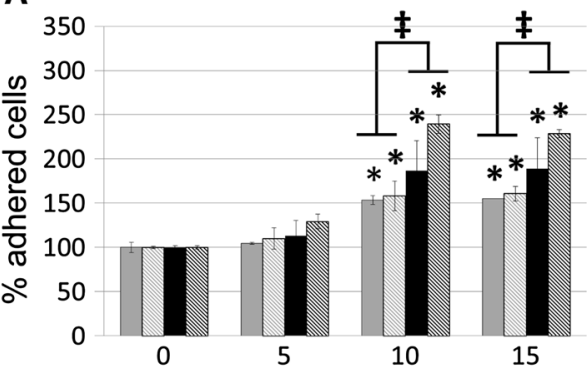

C

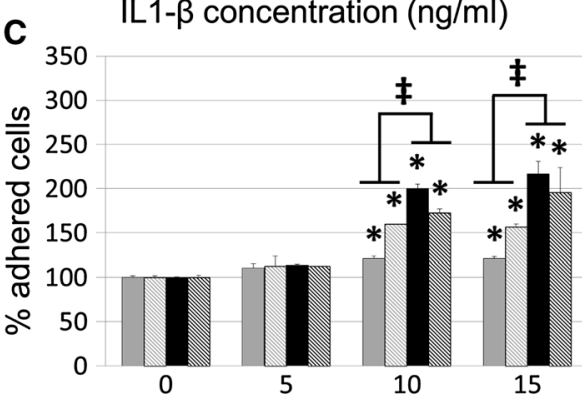

IL1- $\beta$ concentration ( $\mathrm{ng} / \mathrm{ml})$

E

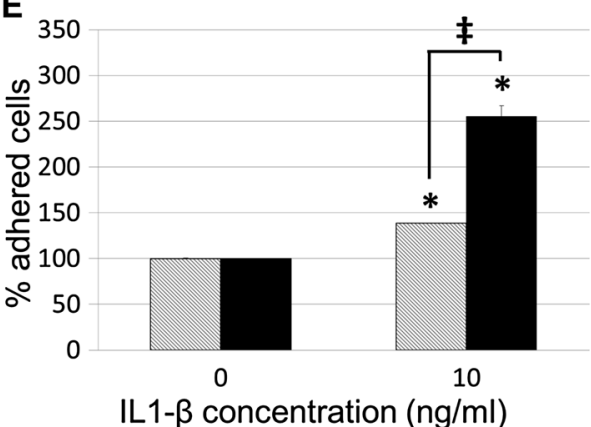

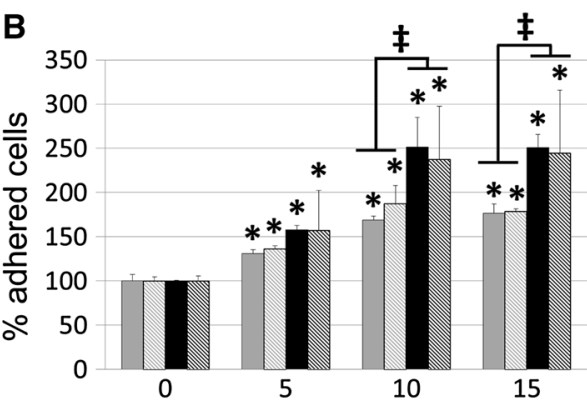

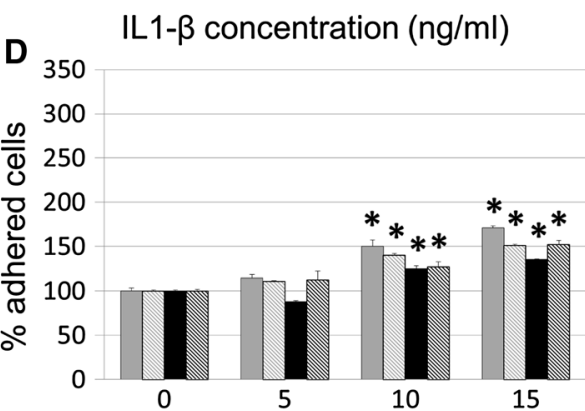

IL1- $\beta$ concentration ( $\mathrm{ng} / \mathrm{ml})$
HUVEC

hMEC-1

hTERT-LEC

HMVEC-dLy Neo 
Fig. 2 MDA-MB-231 adhesion to macrophage conditioned media stimulated hMEC-1 (grey striped) and hTERT-LEC (black) from three different donors $(\mathbf{a}-\mathbf{c})$. Tables indicate macrophage treatment prior to harvesting macrophage conditioned media. LPS LPS stimulation, $T D L$ tumour-derived lysate stimulation, $C 1 i$ caspase- 1 inhibitor. Statistical significance $(P<0.05)$ determined by $t$ test compared to control group is indicated by an asterisk, error bars represent standard deviation. Statistical significance between blood and lymphatic endothelium is represented by double dagger

\section{Activated macrophages promote tumour cell adhesion to endothelial cells}

When macrophages from different donors were activated with LPS they secreted IL-1 $\beta$ at varying levels (18-270 pg/ $\mathrm{ml})$. Supernatants from LPS activated, but not resting, macrophages markedly increased the adhesion of MDAMB-231 or MCF7 cells to lymphatic and blood endothelium (Fig. 2a-c). In contrast, tumour conditioned media had no impact on the adhesion of tumour cells to either endothelium (data not shown). Treatment of macrophages with caspase-1 inhibitor reduced secreted IL-1 $\beta$ production by a mean of $73 \%$ and concomitantly reduced tumour cell adhesion to levels obtained with resting macrophages (Fig. 2a-c). Activation of macrophages in the presence of tumour-derived lysate also ablated their capacity to promote adhesion to endothelial monolayers.

\section{IL-1 $\beta$ supports the migratory ability of tumour cells}

Stimulation of MDA-MB-231 and MCF7 tumour cells with IL-1 $\beta$ caused a significant increase in migration, observed from $2 \mathrm{~h}$ in MDA-MB-231 cells and from $24 \mathrm{~h}$ in MCF7 cells (Fig. 3a, b). In contrast, tumour-conditioned media did not alter migration of MDA-MB-231 or MCF7 cells (data not shown). Two of the three macrophage-conditioned media significantly increased migration of MDA-MB-231 (Fig. 3c). It was noted that macrophage-derived IL-1 $\beta$ levels in the responding donors were 270 and $137 \mathrm{pg} / \mathrm{ml}$ whilst for the non-responding donor there was a much lower level $(20 \mathrm{pg} / \mathrm{ml})$. Further analysis showed that the level of IL-1 $\beta$ secreted by activated macrophages corresponded with the rate of tumour cell migration.

We previously established that the primary route of breast tumour metastasis is through lymphatic vessels [2]. We therefore determined the relative capacity of breast tumour cells to traverse blood or lymphatic vessels. A tissue culture model was established using monolayers of blood (hMEC-1) or lymphatic endothelial cells (hTERT-LEC) and the migration of cell lines studied. The addition of IL-1- $\beta$ to the endothelial monolayer significantly increased tumour cell migration (Fig. 4a). However, there was no preference for migration through lymphatic monolayers. Addition of the conditioned medium from activated macrophages
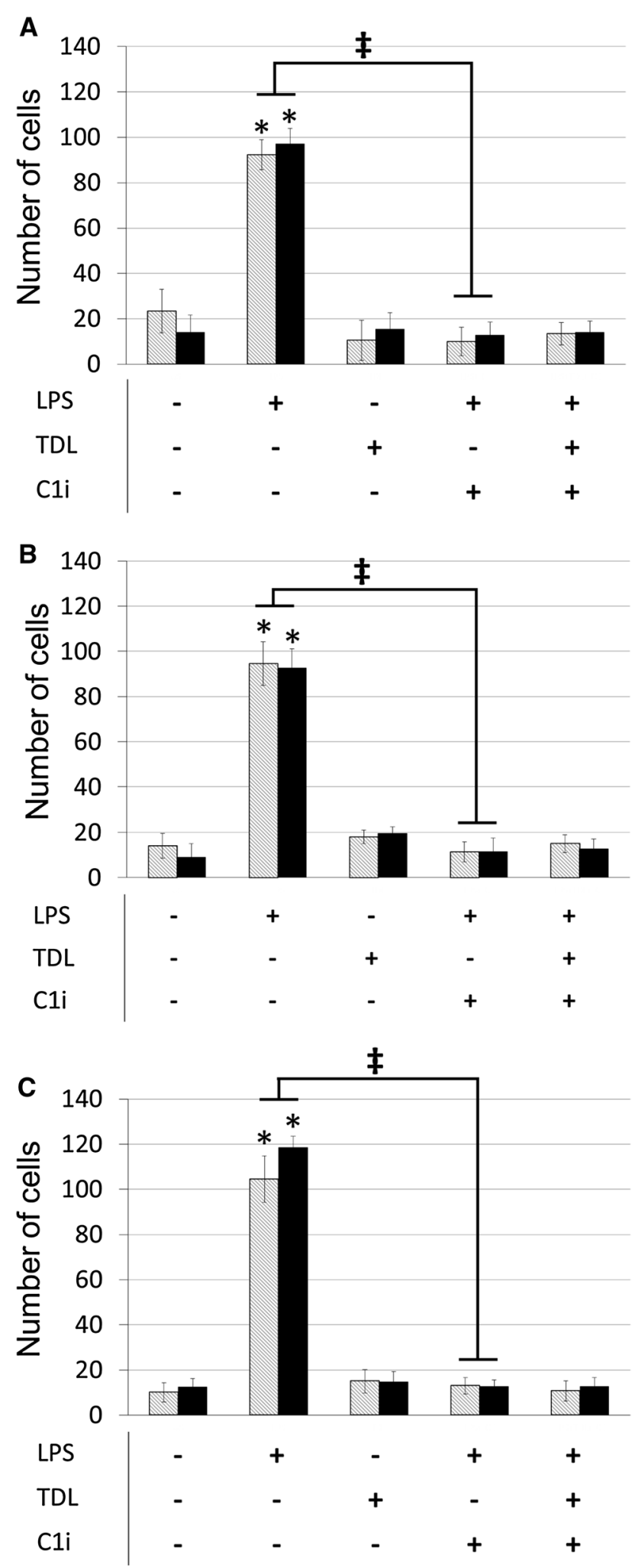

increased the transmigration of MDA-MB-231 cells through both blood and lymphatic endothelial cell barriers (Fig. 4b-d). Importantly, the increased level of transmigration was abrogated by inclusion of a caspase-1 inhibitor. 
A

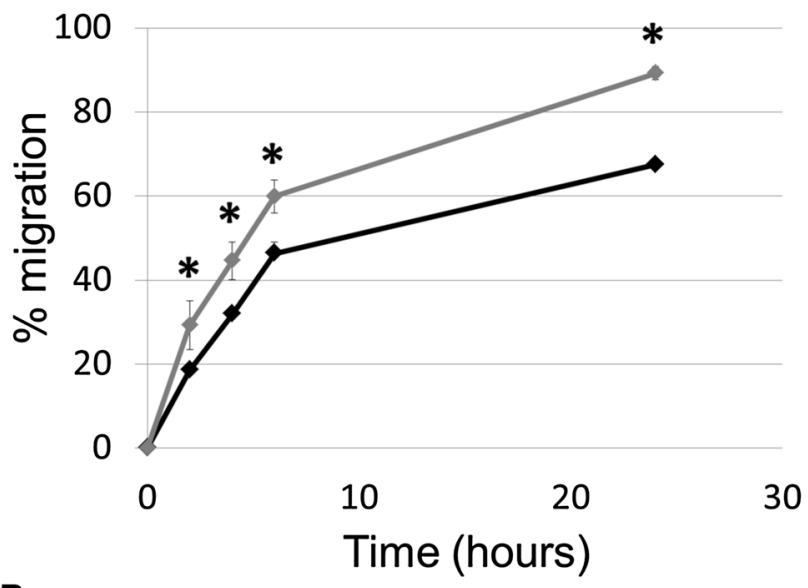

B
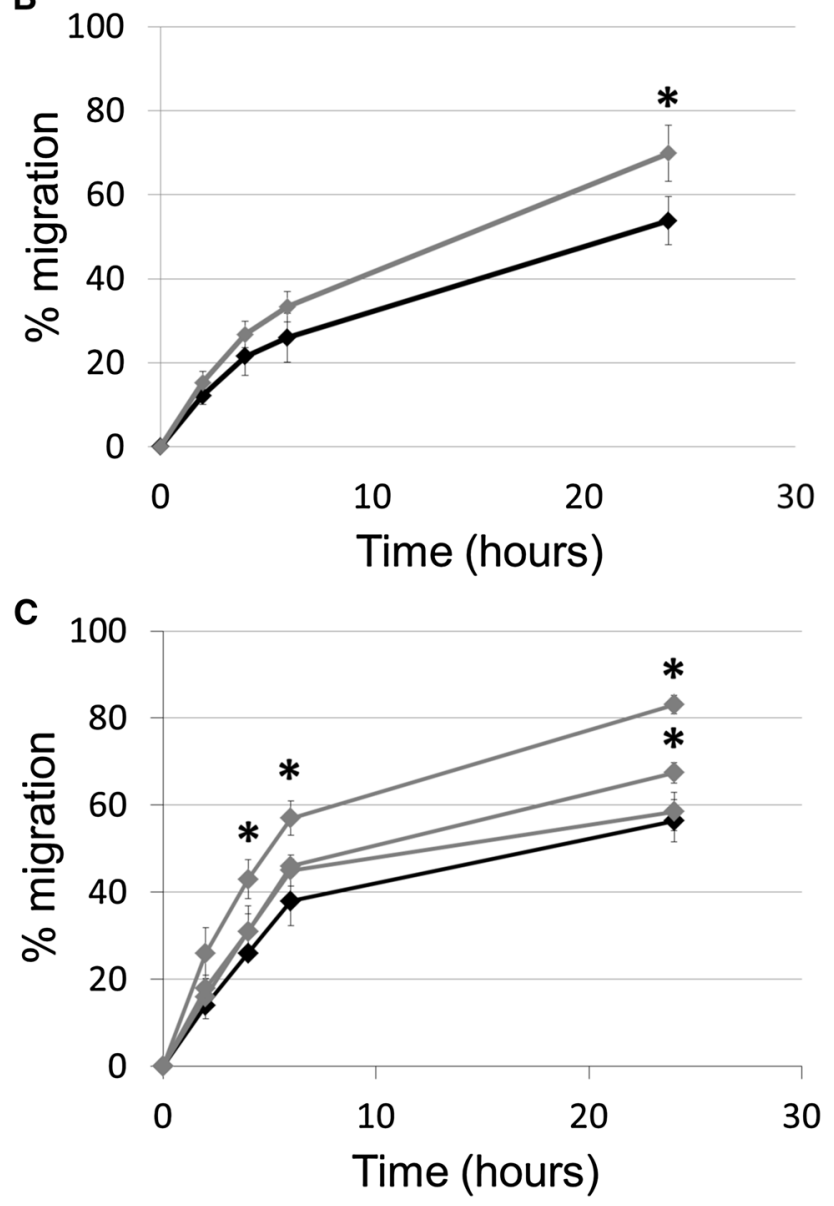

Fig. 3 a MDA-MB-231 migration in control conditions (black line) or following stimulation with IL-1 $\beta$ (grey line). b MCF7 migration in control conditions (black line) or following stimulation with IL-1 $\beta$ (grey line). c MDA-MB-231 migration in control conditions (black line) or following stimulation with macrophage-conditioned media from three individual different donors (grey lines). Statistical significance $(P<0.05)$ determined by $t$ test compared to control group is indicated by an asterisk, error bars represent standard deviation

\section{Discussion}

The aims of this study were to determine the role of IL- $1 \beta$ on adhesion and transmigration to and across endothelial cell monolayers, and whether macrophage might be involved in this process. Studies have shown that lymphatic vessel invasion is more prevalent in patient tumours and is associated with prognosis in numerous tumour types [1, 2].

Following stimulation of endothelial cells with recombinant IL-1 $\beta$, tumour cell adhesion to blood and lymphatic endothelial cell monolayers increased; however, a larger increase was observed in cells of lymphatic origin. Similar results were observed when MDA-MB-231 cells were stimulated with IL-1 $\beta$ and added to unstimulated endothelial cell monolayers. Interestingly, the preference for MCF7 cells to adhere to lymphatic over blood endothelial cell monolayers when the endothelial cells were stimulated with IL-1 $\beta$ was not replicated when the MCF7 cells were stimulated with IL-1 $\beta$ and added to unstimulated endothelial cells. A substantial increase in MDA-MB-231 adhesion was observed following endothelial cell stimulation with macrophage-conditioned media from stimulated macrophages. Interestingly, dual incubation with LPS and a caspase-1 inhibitor ablated the increase in tumour cell adhesion to endothelial cell monolayers and was associated with a large reduction (62$83 \%$ ) in the amount of IL-1 $\beta$ present in the macrophageconditioned media. Tumour-conditioned media had no effect on adhesion and did not contain secreted IL-1 $\beta$, which is in agreement with previous studies [24].

LPS-stimulated macrophage conditioned media increased transmigration of MDA-MB-231 across both blood and lymphatic endothelium, which could be ablated by including a caspase-1 inhibitor; clearly implicating IL-1 $\beta$ as an important mediator in adhesion and transmigration. Interestingly, in two of three macrophage donors, preferential transmigration across lymphatic endothelium was observed. A study has shown the effect of macrophage conditioned media on MCF7 adhesion to HUVEC which could be reduced with endothelin receptor inhibition and showed similar results for transmigration [25].

We postulate that IL-1 $\beta$ may cause differential expression of adhesion molecules on lymphatic over blood endothelium; we observed an increase of both intracellular adhesion molecule (ICAM)-1 and vascular cell adhesion molecule (VCAM)-1 cell surface expression but to equal levels across HUVEC, hMEC-1 and HTERT-LEC following IL-1 $\beta$ stimulation, with no change in common lymphatic endothelial and vascular endothelial receptor (CLEVER)-1 expression (data not shown). IL-1 $\beta$ has, 
Fig. 4 a MDA-MB-231

transmigration across hMEC-1 (grey striped) and hTERT-LEC (black) endothelial cell monolayers under control conditions and following stimulation with IL-1 $\beta$. b-d MDA-MB-231 transmigration across hMEC-1 (grey striped) and hTERT-LEC (black) endothelial cell monolayers following stimulation with macrophage conditioned media from three individual donors. LPS LPS stimulation, $T D L$ tumour-derived lysate stimulation, $C 1 i$ caspase- 1 inhibitor. Statistical significance $(P<0.05)$ determined by $t$ test compared to control group is indicated by an asterisk, error bars represent standard deviation. Statistical significance between blood and lymphatic endothelium is represented by $\ddagger$
A
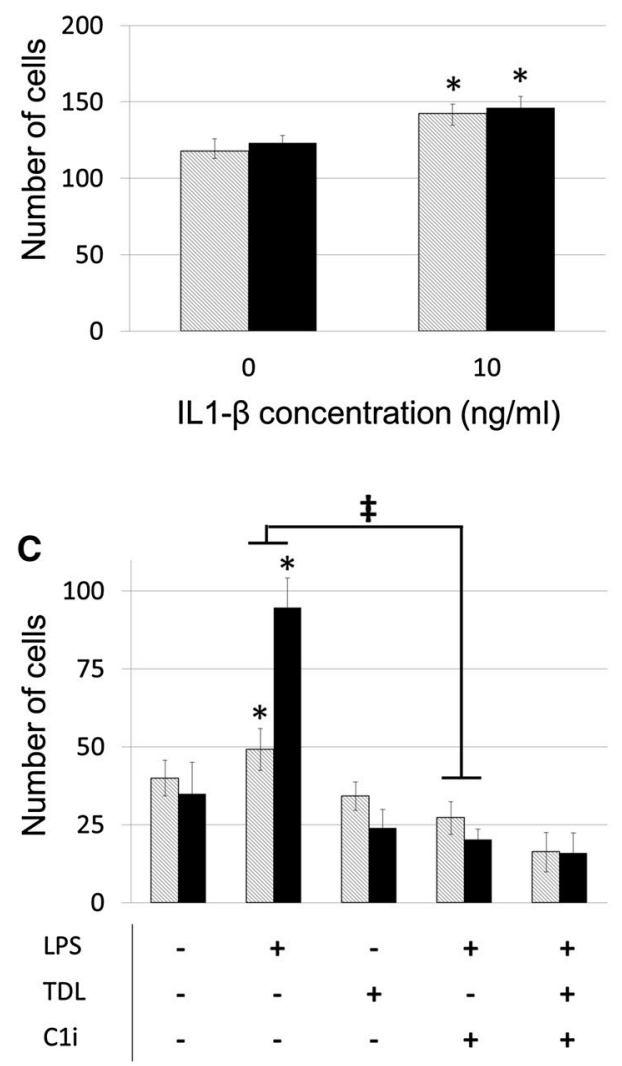
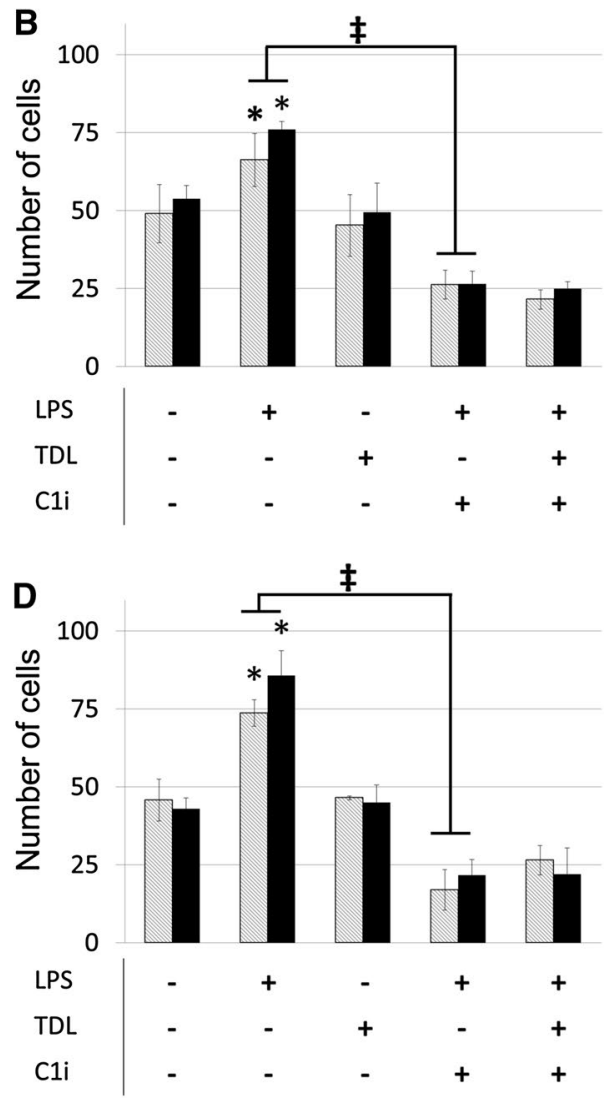

however, been shown to promote metastasis in a number of tumour types, such as lung cancer [26] and melanoma [14].

In addition to adhesion and transmigration, stimulation of both MDA-MB-231 and MCF7 tumour cells with IL-1 $\beta$ increased their migratory ability; furthermore, this increase was also observed with macrophage conditioned media and could be inhibited with a caspase- 1 inhibitor. Previous studies have shown that IL- $1 \beta$ can modulate the migratory potential of MDA-MB-231 cells through accumulation of hypoxia-inducible factor (HIF)- $1 \alpha$, a principal regulator of genes induced by hypoxia [27, 28]. In vivo studies have identified that increased expression of IL-1 $\beta$ is associated with a bone-seeking clone of MDA-MB-231 cells indicating a role for IL- $\beta$ in facilitating bone-homing in the process of bone metastasis [29, 30].

The in vitro studies described modelled single phenotypic events and were able to clearly show that IL- $1 \beta$ or macrophage-derived IL- $1 \beta$ enhanced adhesion, migration and transmigration. These data suggest that IL- $1 \beta$ is important for adhesion and transmigration of tumour cells and is likely to be involved in lymphatic vessel invasion.

Acknowledgements This work was funded by a grant from Breast Cancer Campaign UK (2011NovSP025), who also supported Sarah Storr. (2011MayPr35), with additional support to Andrew Jackson through Matt's Trust Fund for Cancer.

\section{Compliance with ethical standards}

Conflict of interest There are no conflicts of interest to declare.

Open Access This article is distributed under the terms of the Creative Commons Attribution 4.0 International License (http://creativecommons.org/licenses/by/4.0/), which permits unrestricted use, distribution, and reproduction in any medium, provided you give appropriate credit to the original author(s) and the source, provide a link to the Creative Commons license, and indicate if changes were made.

\section{References}

1. Storr SJ, Safuan S, Mitra A, Elliott F, Walker C, Vasko MJ, Ho B, Cook M, Mohammed RA, Patel PM, Ellis IO, Newton-Bishop JA, Martin SG (2012) Objective assessment of blood and lymphatic vessel invasion and association with macrophage infiltration in cutaneous melanoma. Mod Pathol 25(4):493-504. doi:10.1038/modpathol.2011.182

2. Mohammed RA, Martin SG, Gill MS, Green AR, Paish EC, Ellis IO (2007) Improved methods of detection of lymphovascular invasion demonstrate that it is the predominant method of vascular invasion in breast cancer and has important clinical consequences. Am J Surg Pathol 31(12):1825-1833. doi:10.1097/ PAS.0b013e31806841f6

3. Mohammed RA, Martin SG, Mahmmod AM, Macmillan RD, Green AR, Paish EC, Ellis IO (2011) Objective assessment of 
lymphatic and blood vascular invasion in lymph node-negative breast carcinoma: findings from a large case series with longterm follow-up. J Pathol 223(3):358-365. doi:10.1002/path.2810

4. Mohammed RA, Ellis IO, Elsheikh S, Paish EC, Martin SG (2009) Lymphatic and angiogenic characteristics in breast cancer: morphometric analysis and prognostic implications. Breast Cancer Res Treat 113(2):261-273. doi:10.1007/ s10549-008-9936-1

5. Leek RD, Lewis CE, Whitehouse R, Greenall M, Clarke J, Harris AL (1996) Association of macrophage infiltration with angiogenesis and prognosis in invasive breast carcinoma. Cancer Res 56(20):4625-4629

6. Ichimura T, Morikawa T, Kawai T, Nakagawa T, Matsushita H, Kakimi K, Kume H, Ishikawa S, Homma Y, Fukayama M (2014) Prognostic significance of CD204-positive macrophages in upper urinary tract cancer. Ann Surg Oncol 21(6):2105-2112. doi:10.1245/s10434-014-3503-2

7. Pollard JW (2004) Tumour-educated macrophages promote tumour progression and metastasis. Nat Rev Cancer 4(1):71-78. doi: $10.1038 / n r c 1256$

8. Wyckoff JB, Wang Y, Lin EY, Li JF, Goswami S, Stanley ER, Segall JE, Pollard JW, Condeelis J (2007) Direct visualization of macrophage-assisted tumor cell intravasation in mammary tumors. Cancer Res 67(6):2649-2656. doi:10.1158/0008-5472.CAN-06-1823

9. Kang JS, Bae SY, Kim HR, Kim YS, Kim DJ, Cho BJ, Yang HK, Hwang YI, Kim KJ, Park HS, Hwang DH, Cho DJ, Lee WJ (2009) Interleukin-18 increases metastasis and immune escape of stomach cancer via the downregulation of CD70 and maintenance of CD44. Carcinogenesis 30(12):1987-1996. doi:10.1093/ carcin/bgp158

10. Hagemann T, Robinson SC, Schulz M, Trumper L, Balkwill FR, Binder C (2004) Enhanced invasiveness of breast cancer cell lines upon co-cultivation with macrophages is due to TNF-alpha dependent up-regulation of matrix metalloproteases. Carcinogenesis 25(8):1543-1549. doi:10.1093/carcin/bgh146

11. Garlanda C, Dinarello CA, Mantovani A (2013) The interleukin-1 family: back to the future. Immunity 39(6):1003-1018. doi:10.1016/j.immuni.2013.11.010

12. Voronov E, Shouval DS, Krelin Y, Cagnano E, Benharroch D, Iwakura Y, Dinarello CA, Apte RN (2003) IL-1 is required for tumor invasiveness and angiogenesis. Proc Natl Acad Sci USA 100(5):2645-2650. doi:10.1073/pnas.0437939100

13. Jin L, Yuan RQ, Fuchs A, Yao Y, Joseph A, Schwall R, Schnitt SJ, Guida A, Hastings HM, Andres J, Turkel G, Polverini PJ, Goldberg ID, Rosen EM (1997) Expression of interleukin-1beta in human breast carcinoma. Cancer 80(3):421-434

14. Vidal-Vanaclocha F, Fantuzzi G, Mendoza L, Fuentes AM, Anasagasti MJ, Martin J, Carrascal T, Walsh P, Reznikov LL, Kim SH, Novick D, Rubinstein M, Dinarello CA (2000) IL-18 regulates IL-1beta-dependent hepatic melanoma metastasis via vascular cell adhesion molecule-1. Proc Natl Acad Sci USA 97(2):734-739

15. Soria G, Ofri-Shahak M, Haas I, Yaal-Hahoshen N, Leider-Trejo L, Leibovich-Rivkin T, Weitzenfeld P, Meshel T, Shabtai E, Gutman M, Ben-Baruch A (2011) Inflammatory mediators in breast cancer: coordinated expression of TNFalpha and IL-1beta with CCL2 and CCL5 and effects on epithelial-to-mesenchymal transition. BMC Cancer 11:130. doi:10.1186/1471-2407-11-130

16. Winter RN, Kramer A, Borkowski A, Kyprianou N (2001) Loss of caspase-1 and caspase-3 protein expression in human prostate cancer. Cancer Res 61(3):1227-1232

17. Jarry A, Vallette G, Cassagnau E, Moreau A, Bou-Hanna C, Lemarre P, Letessier E, Le Neel JC, Galmiche JP, Laboisse CL (1999) Interleukin 1 and interleukin lbeta converting enzyme (caspase 1) expression in the human colonic epithelial barrier. Caspase 1 downregulation in colon cancer. Gut 45(2):246-251
18. Jaffe EA, Nachman RL, Becker CG, Minick CR (1973) Culture of human endothelial cells derived from umbilical veins. Identification by morphologic and immunologic criteria. J Clin Invest 52(11):2745-2756. doi:10.1172/JCI107470

19. Safuan S, Storr SJ, Patel PM, Martin SG (2012) A comparative study of adhesion of melanoma and breast cancer cells to blood and lymphatic endothelium. Lymphat Res Biol 10(4):173-181. doi:10.1089/lrb.2012.0007

20. Matsuo M, Koizumi K, Yamada S, Tomi M, Takahashi R, Ueda M, Terasaki T, Obinata M, Hosoya K, Ohtani O, Saiki I (2006) Establishment and characterization of conditionally immortalized endothelial cell lines from the thoracic duct and inferior vena cava of tsA58/EGFP double-transgenic rats. Cell Tissue Res 326(3):749-758. doi:10.1007/s00441-006-0229-x

21. Ammar A, Mohammed RA, Salmi M, Pepper M, Paish EC, Ellis IO, Martin SG (2011) Lymphatic expression of CLEVER-1 in breast cancer and its relationship with lymph node metastasis. Anal Cell Pathol (Amst) 34(1-2):67-78. doi:10.3233/ ACP-2011-0002

22. Nisato RE, Harrison JA, Buser R, Orci L, Rinsch C, Montesano R, Dupraz P, Pepper MS (2004) Generation and characterization of telomerase-transfected human lymphatic endothelial cells with an extended life span. Am J Pathol 165(1):11-24. doi:10.1016/S0002-9440(10)63271-3

23. Sheikh S, Gale Z, Rainger GE, Nash GB (2004) Methods for exposing multiple cultures of endothelial cells to different fluid shear stresses and to cytokines, for subsequent analysis of inflammatory function. J Immunol Methods 288(1-2):35-46. doi:10.1016/j.jim.2004.02.005

24. Singer CF, Kronsteiner N, Hudelist G, Marton E, Walter I, Kubista M, Czerwenka K, Schreiber M, Seifert M, Kubista E (2003) Interleukin 1 system and sex steroid receptor expression in human breast cancer: interleukin 1 alpha protein secretion is correlated with malignant phenotype. Clin Cancer Res 9(13):4877-4883

25. Chen CC, Chen LL, Hsu YT, Liu KJ, Fan CS, Huang TS (2014) The endothelin-integrin axis is involved in macrophage-induced breast cancer cell chemotactic interactions with endothelial cells. J Biol Chem 289(14):10029-10044. doi:10.1074/jbc. M113.528406

26. Yano S, Nokihara H, Yamamoto A, Goto H, Ogawa H, Kanematsu T, Miki T, Uehara H, Saijo Y, Nukiwa T, Sone S (2003) Multifunctional interleukin-1beta promotes metastasis of human lung cancer cells in SCID mice via enhanced expression of adhesion-, invasion- and angiogenesis-related molecules. Cancer Sci 94(3):244-252

27. Naldini A, Filippi I, Miglietta D, Moschetta M, Giavazzi R, Carraro $F$ (2010) Interleukin-1beta regulates the migratory potential of MDAMB231 breast cancer cells through the hypoxiainducible factor-1alpha. Eur J Cancer 46(18):3400-3408. doi:10.1016/j.ejca.2010.07.044

28. Filippi I, Carraro F, Naldini A (2015) Interleukin-1beta affects MDAMB231 breast cancer cell migration under hypoxia: role of HIF-1alpha and NFkappaB transcription factors. Mediators Inflamm 2015:789414. doi:10.1155/2015/789414

29. Nutter F, Holen I, Brown HK, Cross SS, Evans CA, Walker M, Coleman RE, Westbrook JA, Selby PJ, Brown JE, Ottewell PD (2014) Different molecular profiles are associated with breast cancer cell homing compared with colonisation of bone: evidence using a novel bone-seeking cell line. Endocr Relat Cancer 21(2):327-341. doi:10.1530/ERC-13-0158

30. Templeton ZS, Lie WR, Wang W, Rosenberg-Hasson Y, Alluri RV, Tamaresis JS, Bachmann MH, Lee K, Maloney WJ, Contag $\mathrm{CH}$, King BL (2015) Breast cancer cell colonization of the human bone marrow adipose tissue niche. Neoplasia 17(12):849-861. doi:10.1016/j.neo.2015.11.005 